\title{
Antibodies to fibroblasts in idiopathic and scleroderma-associated pulmonary
} hypertension

\author{
M.C. Tamby*, M. Humbert" , P. Guilpain*, A. Servettaz*, N. Dupin`, J.J. Christner*, \\ G. Simonneau ${ }^{\#}$, J. Fermanian ${ }^{+}$, B. Weill*, L. Guillevin ${ }^{\S}$ and L. Mouthon*, ${ }^{\star,}, f$
}

ABSTRACT: The aim of the present study was to investigate the presence of anti-fibroblast antibodies in patients with idiopathic or scleroderma-associated pulmonary arterial hypertension (PAH) and healthy controls.

PAH was documented by right-heart catheterisation (mean pulmonary artery pressure at rest $>25 \mathrm{mmHg}$ ). Serum immunoglobulin ( $\mathrm{lg}) \mathrm{G}$ and IgM reactivities of patients with idiopathic PAH $(n=35)$, scleroderma-associated PAH $(n=10)$, diffuse $(n=10)$ or limited cutaneous $(n=10)$ scleroderma without PAH and age- and sex-matched healthy individuals $(n=65)$ were analysed by cell-based ELISA and immunoblotting on normal human fibroblasts.

As assessed by ELISA, 14 out of 35 (40\%) patients with idiopathic PAH and three out of $10(30 \%)$ patients with scleroderma-associated PAH expressed anti-fibroblast IgG antibodies. IgG from all individuals bound to one major 40-kDa protein band. IgG from patients with idiopathic PAH bound to two 25- and 60-kDa bands with a higher intensity than IgG from other individuals.

In conclusion, immunoglobulin $\mathrm{G}$ anti-fibroblast antibodies are present in the serum of patients with pulmonary arterial hypertension. Immunoglobulin G from patients with idiopathic pulmonary arterial hypertension or scleroderma-associated pulmonary arterial hypertension express distinct reactivity profiles with fibroblasts antigens, suggesting distinct target antigens.

\section{KEYWORDS: Anti-fibroblast antibodies, pulmonary arterial hypertension, systemic sclerosis}

$\mathbf{P}$ ulmonary arterial hypertension $(\mathrm{PAH})$ is a rare clinical condition leading to progressive right-heart failure and death [1]. PAH is defined by a mean pulmonary artery pressure $>25 \mathrm{mmHg}$ at rest or $>30 \mathrm{mmHg}$ with exercise in the absence of a post-capillary process as assessed by right-heart catheterisation [2]. $\mathrm{PAH}$ occurs as a consequence of chronic obstruction of small pulmonary arteries secondary to dysfunctions and proliferation of endothelial cells, vascular smooth muscle cells and fibroblasts [3].

According to the World Health Organization classification established in Venice in 2003 [4], $\mathrm{PAH}$ is classified as idiopathic (IPAH), familial or related to other conditions: dexfenfluramine therapy [1], HIV infection [5], portal hypertension, congenital heart disease, and connective tissue diseases such as systemic sclerosis (SSc). Thus, $\sim 10-14 \%$ of SSc patients develop $\mathrm{PAH}$ [6], which is responsible for a high mortality rate.
The formation of a layer of myofibroblasts and extracellular matrix between the endothelium and the internal elastic lamina, termed neointima, is a hallmark of severe PAH. In hypoxia models, adventitial fibroblasts appear to be first cells activated to proliferate and to synthesise matrix proteins in response to pulmonary hypertensive stimulus [7].

To date, very few studies have been conducted to identify autoantibodies in the serum of $\mathrm{PAH}$ patients. A recent study identified anti-endothelial cell immunoglobulin $(\mathrm{Ig}) \mathrm{G}$ antibodies in patients with IPAH or SSc-associated PAH [8]. Since fibroblast dysfunctions have been identified in both SSc and IPAH, and since anti-fibroblast antibodies that are able to activate and induce collagen synthesis have been detected in the serum of SSc patients [9], the current authors analysed the reactivity profiles of anti-fibroblast antibodies in patients with IPAH or SSc-associated PAH and in healthy individuals.
AFFILIATIONS

*Paris-Descartes University, Faculty of Medicine, UPRES-EA 1833,

- Dermatology Dept,

§Internal Medicine Dept,

${ }^{f}$ French National Reference Centre for Necrotizing Vasculitis and Systemic

Sclerosis, Cochin Hospital, and

+Paris-Descartes University, Dept of

Biostatistics, Necker Hospital,

Assistance Publique-Hôpitaux de Paris (AP-HP), Paris, and

\#UPRES-EA 2705, Pneumology Dept and French National Reference Centre for Pulmonary Hypertension, Antoine Béclère Hospital, AP-HP and Paris-Sud University, Clamart, France.

\section{CORRESPONDENCE}

L. Mouthon: Laboratoire d'Immunologie: Pavillon Gustave Roussy: 4e étage, Paris-Descartes University, 8 rue Méchain, 75014, Paris, France. Fax: 33 0144412546

E-mail: luc.mouthon@cch.aphp.fr

Received:

December 282005

Accepted after revision:

May 292006

\section{SUPPORT STATEMENT}

This study was supported by grants from the Institut National de la Santé, de l'Enseignement et de la Recherche Médicale (Contrat de Recherche Stratégique \#4CR08F), the Association des Sclérodermiques de France (ASF), the Legs POIX, Chancellerie des Universités, Académie de Paris, France and a Contrat d'Investigation et de

Recherche Clinique from the Assistance Publique-Hôpitaux de Paris. This study was supported, in part, by the French Network on Pulmonary Arterial Hypertension. M.C. Tamby is a recipient of a grant from Avenir Mutualiste des Professions Libérales \& Indépendantes. P. Guilpain and A. Servettaz received financial support from the Fondation de la Recherche Médicale and ASF, respectively. M.C. Tamby, M. Humbert, A. Servettaz, G. Simonneau, L. Guillevin and $L$. Mouthon are members of Groupe Français de Recherche sur la Sclerodermie (GFRS) 


\section{MATERIALS AND METHODS}

\section{Patients}

All patients gave their written informed consent according to the ethics committee of the La Pitié-Salpêtrière Hospital Group (Paris, France). PAH was detected as systolic pulmonary artery pressure $>40 \mathrm{mmHg}$ upon echocardiography, and confirmed by right-heart catheterisation as mean pulmonary artery pressure at rest $>25 \mathrm{mmHg}$. By convention, $\mathrm{PAH}$ patients were labelled as having IPAH if they displayed PAH with no evidence of an associated disease (corresponding to sporadic, familial and fenfluramine-associated PAH). SSc patients fulfilled the LERoY and MEDSGER [10] and/or the American Rheumatism Association [11] criteria. Sera were obtained from 65 patients: 35 consecutive patients with IPAH (20 with sporadic PAH, 10 with PAH associated with dexfenfluramine exposure and five with familial PAH) at the Pneumology Dept of Antoine Béclère Hospital (Clamart, France); and 30 consecutive SSc patients, including 10 with SSc-associated PAH (SSc-PAH), 10 with limited cutaneous SSc without PAH and 10 with diffuse SSc without PAH, in the Internal Medicine Dept of Cochin Hospital (Paris, France). Disease duration was significantly longer in SSc patients than in IPAH patients (table 1). All patients with diffuse SSc without PAH had interstitial lung disease, as assessed by chest high-resolution computed tomodensitometry, and a vital capacity $<80 \%$ predicted and/or a diffusing capacity of $<75 \%$ pred. None of the patients received corticosteroids or immunosuppressants and none of them had cancer or another connective tissue disease. A total of 65 unrelated age- and sex-matched healthy blood donors were studied as controls.

\section{Immunoglobulin sources}

Serum samples from all patients and healthy controls were stored at $-80^{\circ} \mathrm{C}$ until tested and diluted to $\operatorname{IgG}$ and $\operatorname{IgM}$ concentrations of 100 and $20 \mu \mathrm{g} \cdot \mathrm{mL}^{-1}$ respectively, when tested. IgG and IgM antibody concentrations were determined by nephelometry. A therapeutic preparation of normal human IgG (i.v. immunoglobulin; Tegeline ${ }^{\circledR}$; Laboratoire Français du Fractionnement Biologique et des Biotechnologies, Les Ulis, France) and normal human polyclonal IgM (Laboratoire Français du Fractionnement Biologique et des Biotechnologies) served as internal standards.

\section{Cell culture}

Normal human dermal fibroblasts were cultured from normal skin. Biopsy specimens were cut and seeded into Petri dishes and cultured as previously described [9]. Human epithelial (HEp)-2 cells were obtained and cultured as previously reported [8].

\section{ELISA detection of anti-fibroblast antibodies}

A cell-based ELISA was performed on fixed and unpermeabilised fibroblasts [12]. In order to adjust for interassay variability, the optical density value of a positive reference serum was arbitrarily defined as $100 \%$ of anti-fibroblast activity. The results of tested samples were expressed as a percentage of this positive reference value. All samples were tested in duplicate.

\section{Immunoblotting detection of anti-fibroblast and anti-HEp-2 cell antibodies}

Antibody reactivities were analysed using a semiquantitative immunoblotting technique with normal human fibroblasts and HEp-2 cells.

Cellular protein extraction was performed in a buffer containing $4 \%$ sodium dodecyl sulphate (SDS), $1.45 \mathrm{M}$ 2-mercaptoethanol, $125 \mathrm{mM}$ Tris $/ \mathrm{HCl} \mathrm{pH} 6.8,1 \mu \mathrm{g} \cdot \mathrm{mL}^{-1}$ aprotinin, $1 \mu \mathrm{g} \cdot \mathrm{mL}^{-1}$ pepstatin and $1 \mu \mathrm{g} \cdot \mathrm{mL}^{-1}$ leupeptin and then sonicated $4 \times 30 \mathrm{~s}$. Equal amounts of solubilised proteins were subjected to preparative SDS-polyacrylamide gel electrophoresis through $10 \%$ polyacrylamide gels. The proteins were transferred to nitrocellulose membrane for $1 \mathrm{~h}$ at $0.8 \mathrm{~mA} \cdot \mathrm{cm}^{-2}$

TABLE 1 Clinical and immunological characteristics of patients

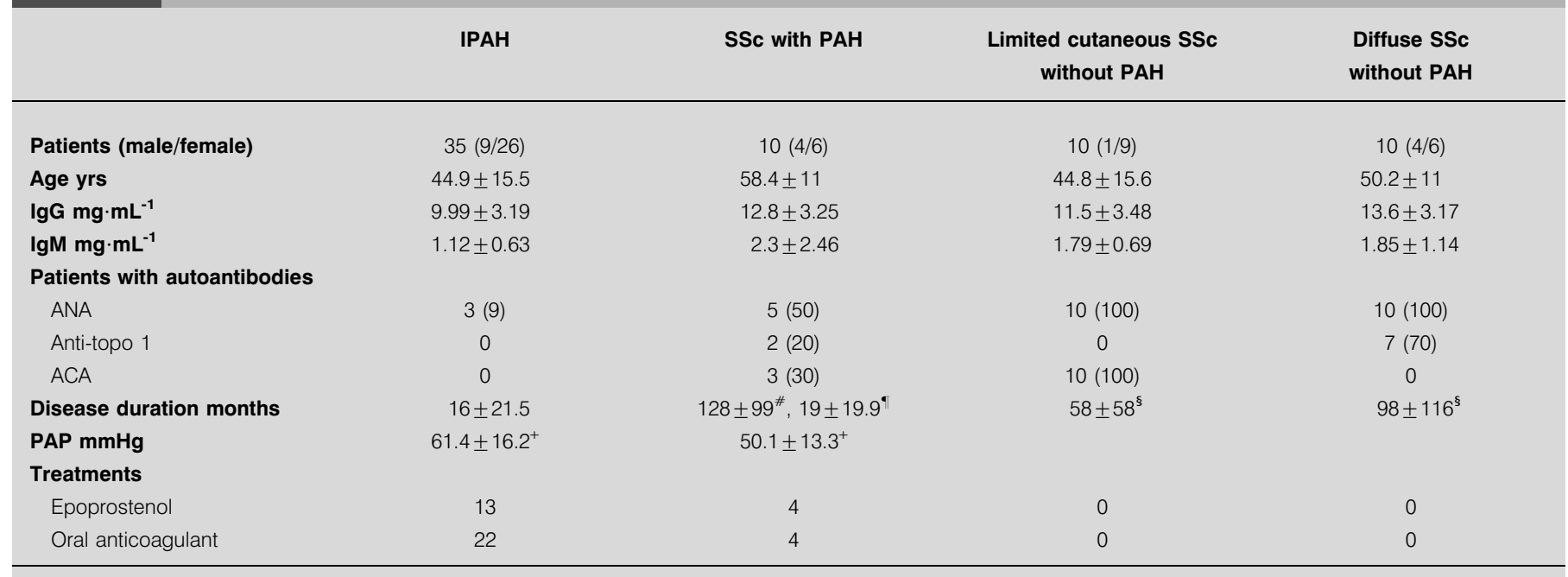

Data are presented as $\mathrm{n}$, mean \pm SD and $\mathrm{n}(\%)$. IPAH: idiopathic pulmonary arterial hypertension; SSc: systemic sclerosis; PAH: pulmonary arterial hypertension; ANA: anti-nuclear antibodies; anti-topo 1: anti-topoisomerase 1 antibodies; ACA: anti-centromere antibodies; PAP: pulmonary artery pressure. ${ }^{*}$ : disease duration of SSc; ${ }^{\text {. }}$ disease duration of $\mathrm{PAH} ;{ }^{+}$: mean PAP as measured by right-heart catheterisation; ${ }^{\S}$ : systolic $\mathrm{PAP}<35 \mathrm{mmHg}$ as measured by echocardiography. $1 \mathrm{mmHg}=0.133 \mathrm{kPa}$ 
using a semi-dry electroblotter (model A; Ancos, Hojby, Denmark). After blocking with PBS- $0.2 \%$ Tween for 90 min, the membranes were incubated with sera for $4 \mathrm{~h}$ at room temperature, at $100 \mu \mathrm{g} \cdot \mathrm{mL}^{-1} \mathrm{IgG}$ or $20 \mu \mathrm{g} \cdot \mathrm{mL}^{-1} \mathrm{IgM}$ in a Cassette Miniblot System (Immunetics Inc., Cambridge, MA, USA). They were then extensively washed before being incubated with either secondary rabbit anti-human crystallisable fragment $\left(\mathrm{Fc}_{\mathrm{c}}\right)-\gamma$ or $\mathrm{Fc}_{\mathrm{c}} \mu$ antibody coupled to alkaline phosphatase (Dako, Glostrup, Denmark) for $90 \mathrm{~min}$ at room temperature. Immunoreactivities were revealed using the nitroblue tetrazolium-5-bromo-4-chloro-3-indolyl-phosphate substrate (Sigma-Aldrich, St Louis, MO, USA). Immunoreactivities were quantified by scanning the membranes with a densitometer (Epson Perfection 1200S; Seiko Epson Corporation, Nagano-Ken, Japan). The membranes were then stained with colloidal gold (Protogold $₫$; Biocell, Cardiff, UK) and subjected to a second densitometric analysis to quantify transferred proteins. This approach allows the immunoreactivity repertoires to be compared by referring to their respective protein peaks corrected for electrophoretic migration defects by superimposing corresponding protein peaks using computer analysis. Standard IgG or IgM preparations, included in each blot, allow rescaling of the membranes transferred with a given protein extract and adjustment for the intensity of labelling on different membranes [13, 14].

\section{Statistical analyses}

For the analysis of ELISA data, the mean relative optical densities of two groups were compared using the t-test. Immunoblotting data were submitted to multivariate statistical analysis because of the large number of reactivities revealed. Therefore, IGOR software (Igor Pro 3.16, Wavemetrics Inc, Lake Oswego, OR, USA) with specially designed packages and Systat software (version 11.0, Systat Software Inc., Point Richmond, CA, USA), were used. Densitometry curves of the IgG and IgM reactivities of each patient and controls on each of the different protein extracts were divided into sections surrounding individual peaks of immunoreactivity on each substrate. Eight to ten sections were selected, depending on the protein extract used and number of antibody reactivities identified in the blots. The number of comparisons performed was limited on a basis of clinical relevance, and five comparisons were performed for IgG and for IgM reactivities: all PAH patients versus healthy controls; IPAH patients versus healthy controls; SSc-PAH patients versus healthy controls; IPAH patients versus SSc-PAH patients; and SSc-PAH patients versus SSc patients without PAH . In order to compare groups of individuals (groups of patients two by two and patients and controls), for each comparison, the factor scores of each of the subjects were calculated after performing factor analysis of the whole data $[8,15]$. Factor scores were submitted either to a paired Wilcoxon test to compare repertoires of reactivities of patients to age- and sex-matched healthy controls, or to a Mann-Whitney U-test to compare repertoires of reactivities of patients two by two. The number and the molecular weights of contributing protein bands varied according to the source of antigens tested and the two groups compared [8, 13].

\section{RESULTS}

\section{ELISA detection of anti-fibroblast IgG antibodies}

The serum IgG reactivities to fibroblasts of IPAH patients, SSc patients with or without PAH and healthy controls were tested using a cell-based ELISA. Using a threshold defined by two standard deviations over the mean optical density of IgG reactivities of healthy individuals, 14 out of 35 (40\%) IPAH patients, three out of 10 (30\%) SSc-PAH patients, one out of 10 $(10 \%)$ limited cutaneous SSc without PAH patients, three out of $10(30 \%)$ diffuse SSc without PAH patients and two out of 65 (3.1\%) healthy individuals had anti-fibroblast antibodies (fig. 1). When the threshold was moved to three standard deviations over the mean optical density of healthy controls, 10 out of $35(28.6 \%)$ IPAH patients, three out of $10(30 \%)$ SSc-PAH patients, one out of $10(10 \%)$ limited cutaneous SSc without PAH patients, two out of $10(20 \%)$ diffuse SSc without PAH patients but none of the healthy controls had anti-fibroblast antibodies (fig. 1). The mean IgG anti-fibroblast antibody serum levels of patients with IPAH, SSc-PAH patients and diffuse SSc without PAH patients were significantly higher than those of healthy individuals (fig. 1), whereas the mean IgG anti-fibroblast antibody serum levels of limited cutaneous SSc patients without PAH were not. No significant differences were observed between the mean serum levels of IgG antifibroblast antibodies of the different groups of patients.

\section{Immunoblot detection of anti-fibroblast IgG reactivities}

Serum IgG reactivity patterns were homogeneous among healthy individuals and patients within each group. However, IgG antibodies from a few healthy individuals and patients in each group bound to unique bands with high intensity. IgG from all patients and healthy individuals bound to one major protein band of $40 \mathrm{kDa}$ (figs 2 and 3). IgG from IPAH patients bound to two 25- and 60-kDa bands with a higher intensity than IgG from other individuals. In addition, IgG antibodies from healthy controls and all patients except

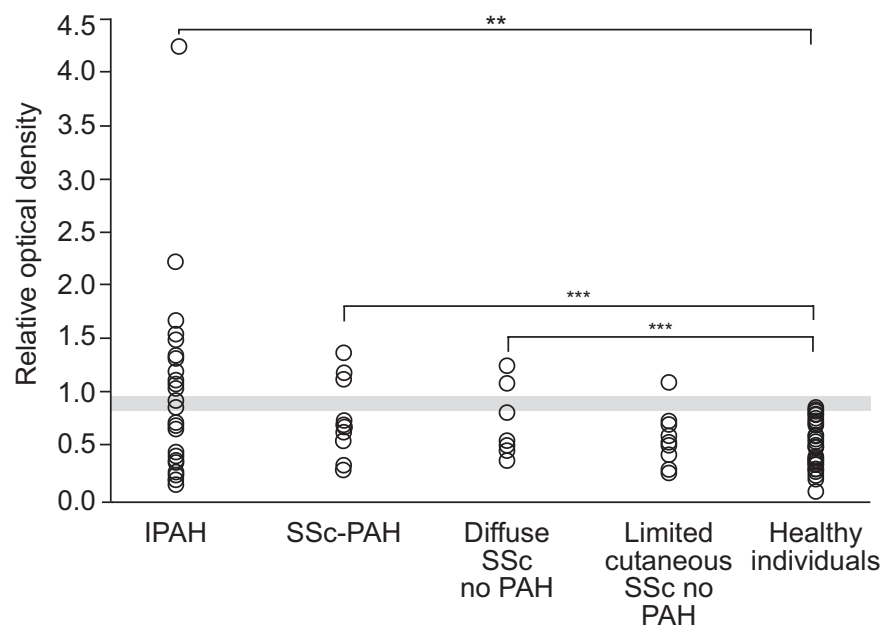

FIGURE 1. Cell-based ELISA detection of anti-fibroblast antibodies. Serum immunoglobulin G from idiopathic pulmonary arterial hypertension (IPAH) patients, systemic sclerosis-associated pulmonary arterial hypertension (SSc-PAH) patients, limited cutaneous and diffuse SSc patients without pulmonary arterial hypertension and age- and sex-matched healthy individuals was tested at $100 \mu \mathrm{g} \cdot \mathrm{mL}^{-1}$ with fixed unpermeabilised normal human dermal fibroblasts. The lower and upper limits of the shaded area represent the $+2 \mathrm{SD}$ and $+3 \mathrm{SD}$ thresholds defined as the mean optical density value obtained in healthy individuals. Significant differences between patients and healthy individuals as assessed by using a t-test are indicated. **: $p<0.01 ; * * *: p<0.001$ 

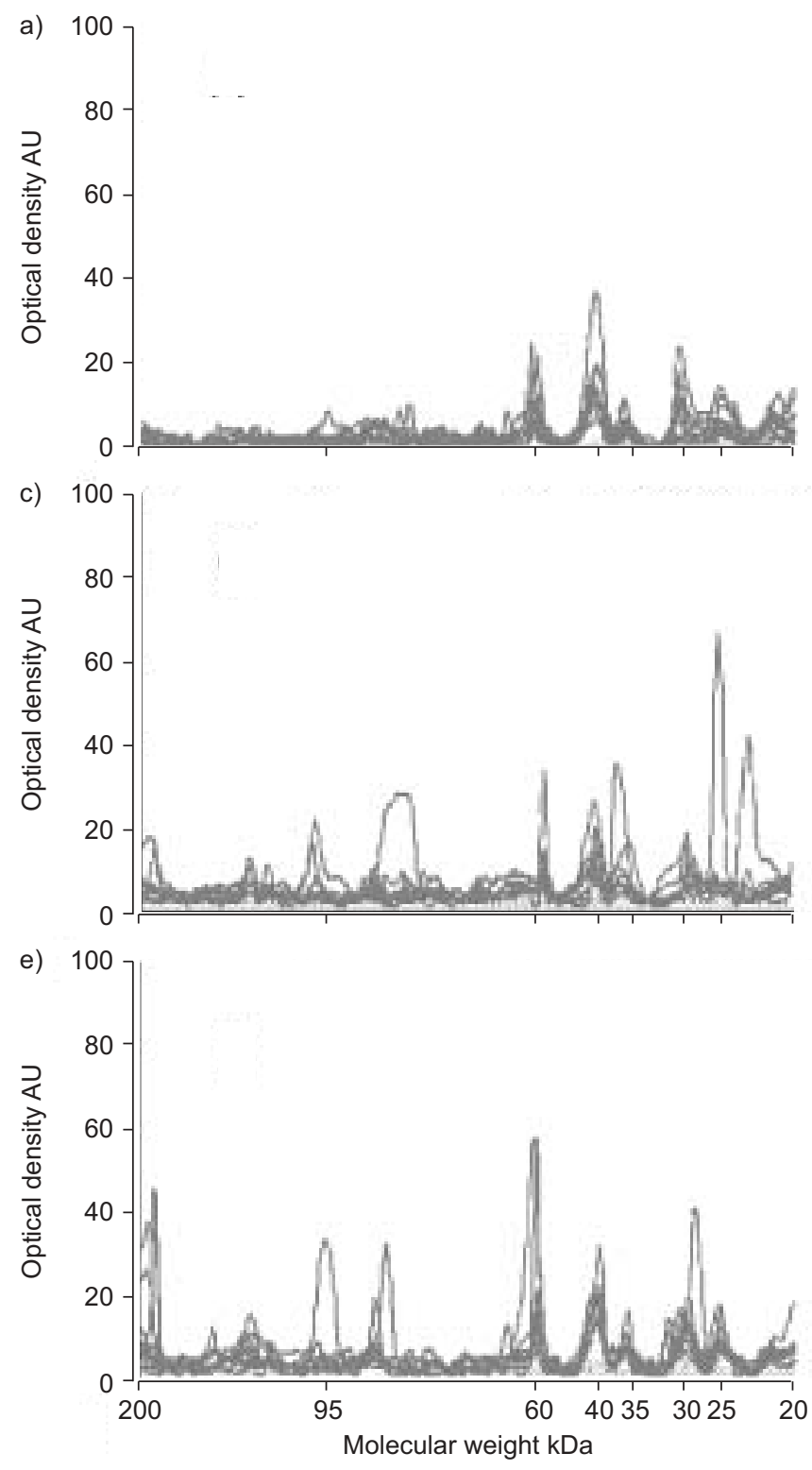

those with limited cutaneous SSc without PAH bound to a 30kDa fibroblast protein (table 2).

\section{Immunoblot detection of anti-HEp-2 cell IgG antibodies}

In order to document the fibroblast specificity of IgG reactivities, additional experiments were performed using a protein extract from HEp-2 cells, a reference substrate for the identification of anti-nuclear antibodies. Healthy individuals and IPAH patients expressed a low number of reactivities, with one major IgG reactivity directed toward a 40-kDa protein band. In contrast, SSc patients in the different groups expressed a large number of $\mathrm{IgG}$ reactivities, with two major protein bands of 75 and $85 \mathrm{kDa}$ in SSc-PAH patients or in patients with limited cutaneous SSc without PAH, and two major protein bands of 70 and $95 \mathrm{kDa}$ in patients with diffuse SSc (fig. 4; table 2). b)

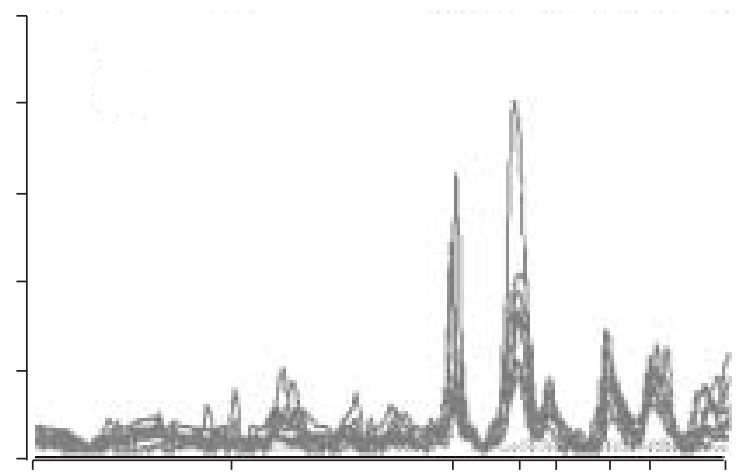

d)

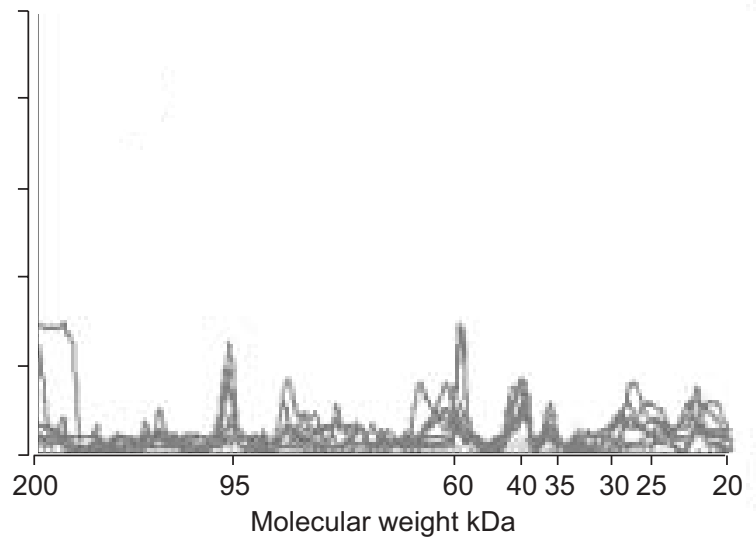

FIGURE 2. Densitometric profiles of immunoglobulin (lg)G reactivity of a) 10 healthy individuals; b) 10 patients with idiopathic pulmonary arterial hypertension; c) 10 systemic sclerosis (SSc)-associated pulmonary arterial hypertension (PAH) patients; d) 10 patients with limited cutaneous SSc without PAH; and e) 10 patients with diffuse SSc without $\mathrm{PAH}$, to normal human fibroblast antigens. Sera were diluted to an IgG concentration of $100 \mu \mathrm{g} \cdot \mathrm{mL}^{-1}$. The densitometric pattern of $\mathrm{IgG}$ reactivities of each individual is depicted as a full-line curve. Shaded areas depict the densitometric pattern observed in the presence of the secondary anti-crystallisable fragment- $\gamma$ antibody alone. Molecular weights are expressed as $\mathrm{kDa}$ in the abscissa, and optical densities are expressed as arbitrary units (AU) in the ordinates.

\section{Comparison of the factor scores of the serum anti- fibroblast and anti-HEp-2 cell IgG reactivities of IPAH patients, SSc patients with or without PAH and healthy controls}

IgG anti-fibroblast reactivities differed significantly between PAH patients and healthy controls and between IPAH patients and healthy controls, but not between SSc-PAH patients and controls (table 3). Anti-HEp-2 cell IgG reactivities did not differ significantly between healthy controls and $\mathrm{PAH}$ patients (table 3). IgG anti-fibroblast reactivities did not differ significantly between IPAH and SSc-PAH patients or between SSc$\mathrm{PAH}$ patients and SSc patients without PAH, whereas IgG anti-HEp-2 cell reactivities differed significantly between the same groups for factors 1 and 3 of the analysis corresponding to reactivities of $25,30,35,50,75$ and $85 \mathrm{kDa}$ for factor 1 and 70 and $95 \mathrm{kDa}$ or 25, 35 and $40 \mathrm{kDa}$ for factor 3, respectively (table 4). 


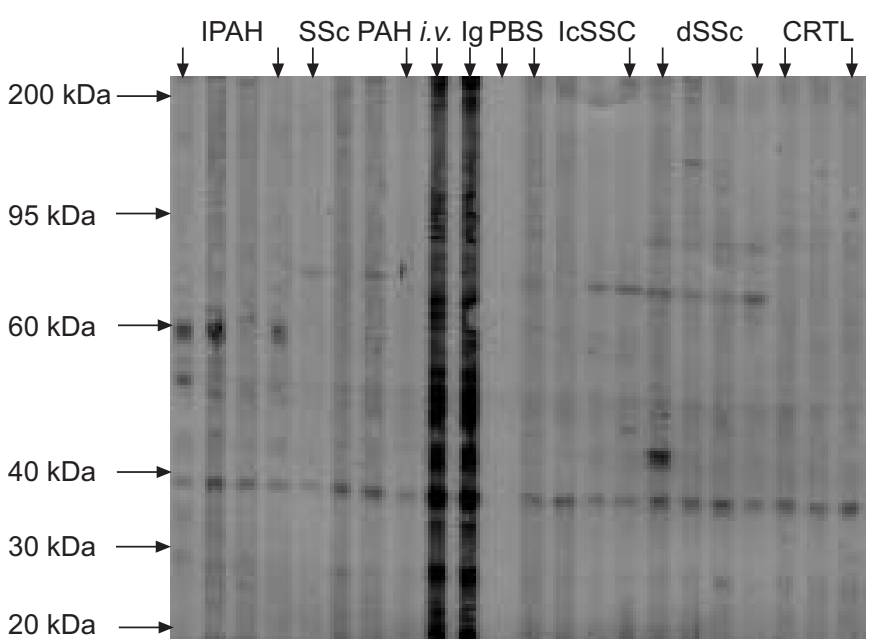

FIGURE 3. Western blotting of immunoglobulin (Ig)G with fibroblast protein extracts. Serum IgG from idiopathic pulmonary hypertension (IPAH) patients; systemic sclerosis (SSc)-associated pulmonary arterial hypertension (PAH) patients; limited cutaneous (IC) and diffuse (d) SSc patients without PAH; and age- and sex-matched healthy controls was immunoblotted at $100 \mu \mathrm{g} \cdot \mathrm{mL}^{-1}$ with a soluble extract of normal human dermal fibroblasts. Normal human polyclonal IgG (intravenous immunoglobulin (i.v. Ig)) and secondary anti-crystallisable fragment- $\gamma$ antibody tested alone were used as positive and negative controls, respectively.

\section{Detection of anti-fibroblast IgM reactivities}

The serum IgM reactivities to fibroblasts of patients with IPAH and SSc-PAH, and SSc without PAH, as well as healthy controls, were tested using cell-based ELISA. Using a threshold defined by two standard deviations over the mean optical density of IgM reactivities of healthy individuals, none of the patients and healthy controls expressed anti-fibroblast antibodies (data not shown).

When tested by immunoblotting, serum IgM reactivity patterns were homogeneous among healthy individuals and patients in each group. IgM antibodies from a few healthy individuals and patients in each group bound to unique bands with high intensity. IgM from all patients and healthy individuals bound to one major protein band of $40 \mathrm{kDa}$ (table 2).

\section{Comparison of the factors scores of the serum anti- fibroblast and anti-HEp-2 cells IgM reactivities of IPAH patients, SSc patients with or without PAH and healthy controls}

IgM anti-fibroblast reactivities differed significantly between PAH patients and healthy controls and between IPAH patients and healthy controls, but not between SSc-PAH patients and healthy controls (table 3). Anti-nuclear IgM reactivities did not differ significantly between healthy controls and PAH patients (table 3). IgM anti-fibroblast and anti-HEp-2 cell reactivities

TABLE 2 Serum immunoglobulin (Ig)G and lgM reactivities of patients with idiopathic pulmonary arterial hypertension (IPAH), systemic sclerosis (SSc) patients with or without pulmonary arterial hypertension (PAH) and healthy individuals to fibroblast and human epithelial (HEp)-2 cell antigens

\begin{tabular}{|c|c|c|c|c|}
\hline \multirow{2}{*}{ Patient groups/antigen sources } & \multicolumn{2}{|c|}{ Fibroblasts } & \multicolumn{2}{|c|}{ HEp-2 cell } \\
\hline & $\lg G$ & $\lg M$ & $\lg G$ & $\lg M$ \\
\hline Reactivity peaks $n$ & $6-8$ & $5-7$ & $4-6$ & $6-10$ \\
\hline Main reactivity(ies) $\mathrm{kDa}(\mathrm{n} / \mathrm{N})$ & $\begin{array}{c}25(12 / 65) ; 30(16 / 65) ; \\
35(4 / 65) ; 40(34 / 65) ; 60(19 / 65)\end{array}$ & $\begin{array}{l}35(5 / 65) ; 45(6 / 65) ; \\
55(40 / 65) ; 65(3 / 65)\end{array}$ & $\begin{array}{l}25(28 / 65) ; 35(17 / 65) \\
40(15 / 65) ; 70(6 / 65)\end{array}$ & $\begin{array}{l}25(48 / 65) ; 35(45 / 65) ; \\
45(47 / 65) ; 55(50 / 65) ; \\
65(57 / 65) ; 70(52 / 65)\end{array}$ \\
\hline \multicolumn{5}{|l|}{ IPAH } \\
\hline Reactivity peaks $n$ & $7-9$ & & $4-6$ & $6-10$ \\
\hline Main reactivity(ies) $\mathrm{kDa}(\mathrm{n} / \mathrm{N})$ & $\begin{array}{c}25(11 / 35) ; 30(17 / 35) \\
35(3 / 35) ; 40(21 / 35) \\
60(12 / 35)\end{array}$ & $\begin{array}{l}25(4 / 35) ; 35(2 / 35) ; 45(10 / 35) ; \\
55(10 / 35) ; 65(3 / 35) ; 70(3 / 35)\end{array}$ & $\begin{array}{l}25(26 / 35) ; 30(9 / 35) \\
35(21 / 35) ; 40(12 / 35) ;\end{array}$ & $\begin{array}{c}25(28 / 35) ; 35(26 / 35) ; 45(29 / \\
35) ; 55(28 / 35) ; 65(32 / 35) ; \\
70(25 / 35)\end{array}$ \\
\hline \multicolumn{5}{|l|}{ SSc with PAH } \\
\hline Reactivity peaks $n$ & $6-8$ & & $8-10$ & $6-10$ \\
\hline Main reactivity(ies) kDa (n/N) & $\begin{array}{l}25(2 / 10) ; 30(2 / 10) ; 35(2 / 10) ; \\
40(6 / 10) ; 60(3 / 10) ; 75(4 / 10)\end{array}$ & $45(2 / 10) ; 55$ (5/10); & $\begin{array}{l}40(2 / 10) ; 70(3 / 10) \\
75(3 / 10) ; 85(2 / 10)\end{array}$ & $\begin{array}{l}25(8 / 10) ; 35(7 / 10) ; 45(8 / 10) ; \\
55 \text { (10/10); } 65(8 / 10) ; 70(8 / 10)\end{array}$ \\
\hline \multicolumn{5}{|l|}{ Diffuse SSc without PAH } \\
\hline Reactivity peaks $n$ & $6-8$ & $2-5$ & $6-9$ & $6-10$ \\
\hline Main reactivity(ies) kDa (n/N) & $\begin{array}{c}25(4 / 10) ; 30(6 / 10) ; 35(2 / 10) ; 40 \\
(9 / 10) ; 60(6 / 10) ; 70(3 / 10) ; \\
95(3 / 10)\end{array}$ & 45 (8/10); 55 (10/10) & $\begin{array}{c}25(4 / 10) ; 35(3 / 10) ; \\
40(5 / 10) ; 70(6 / 10) ; 95(1 / 10)\end{array}$ & $\begin{array}{l}25 \text { (9/10); } 35 \text { (7/10); } 45 \text { (7/10); } \\
55 \text { (8/10); } 65 \text { (10/10); } 70(7 / 10)\end{array}$ \\
\hline
\end{tabular}



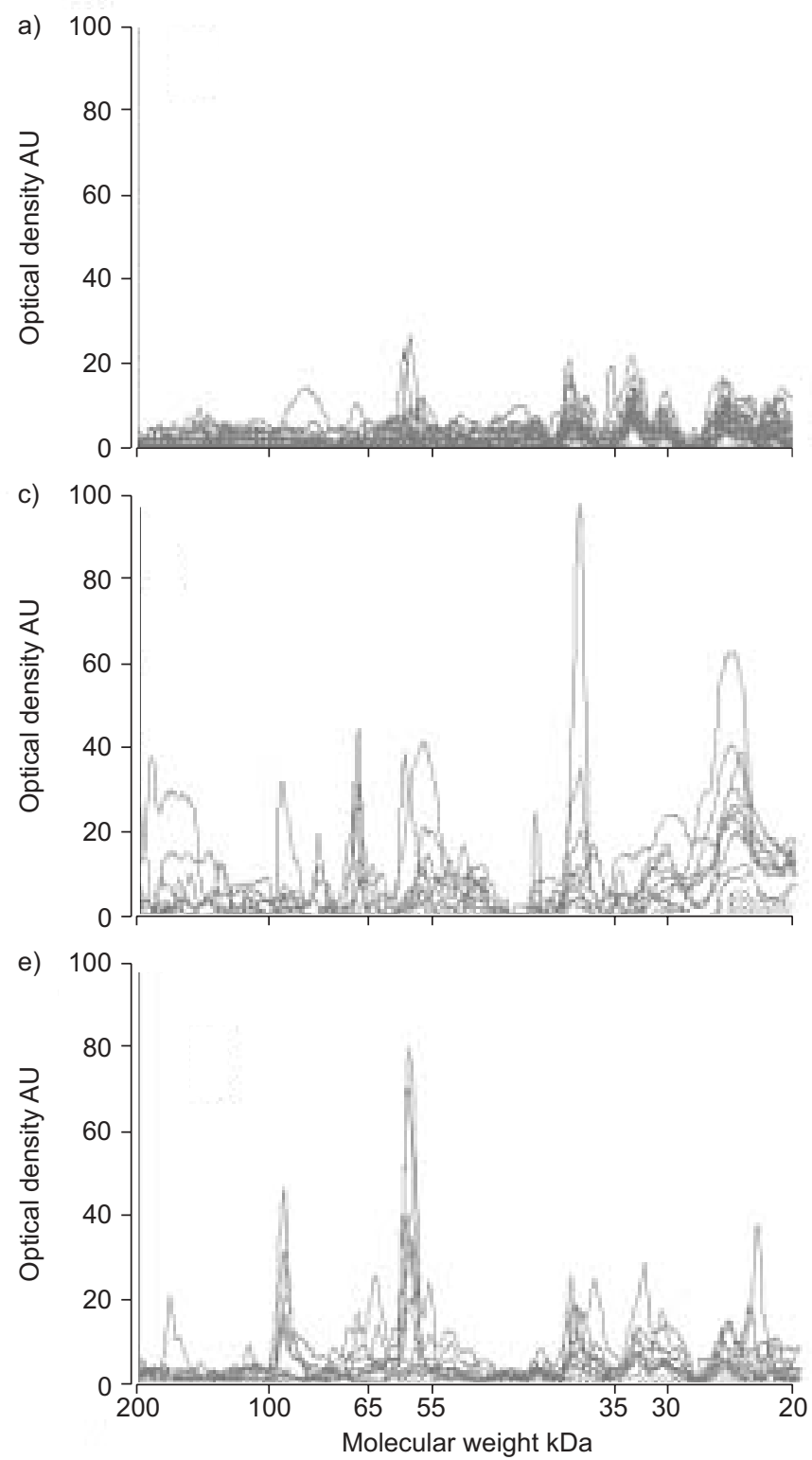

did not differ significantly between IPAH and SSc-PAH patients or between SSc-PAH patients and SSc patients without PAH (table 4).

\section{DISCUSSION}

The present study has demonstrated for the first time that IgG and IgM anti-fibroblast antibodies are present in the serum of patients with $\mathrm{PAH}$, with distinct reactivity patterns in IPAH and SSc-associated PAH.

It is well established that SSc patients express anti-fibroblast antibodies [9, 16, 17]. In the current study, anti-fibroblast antibodies have been evidenced in $25 \%$ of SSc patients without $\mathrm{PAH}$ and in $30 \%$ of SSc patients with $\mathrm{PAH}$, whereas CHIZZOLINI et al. [9] detected anti-fibroblast antibodies in 58\% of SSc patients using cell-based ELISA. In SSc patients, anti-fibroblast antibodies have previously been shown to induce fibroblast activation in vitro and a pro-adhesive and pro-inflammatory b)

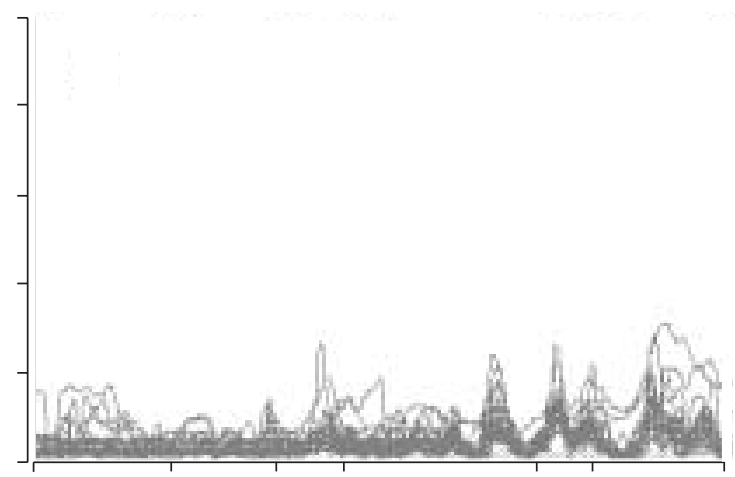

d)

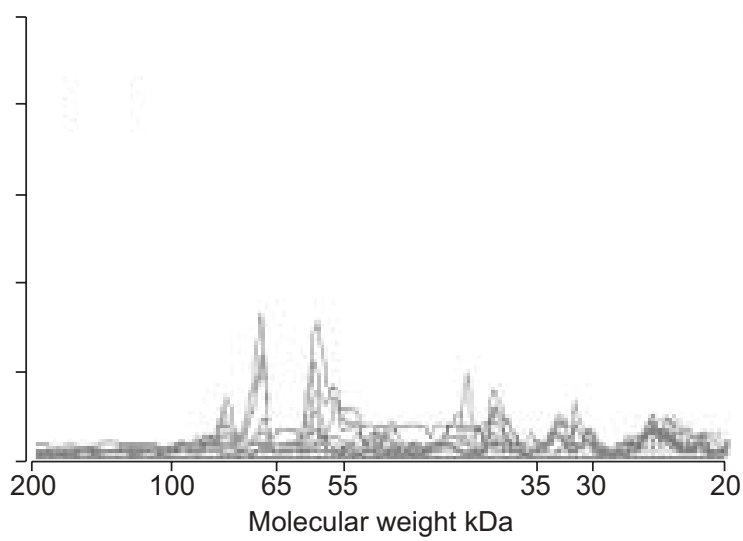

FIGURE 4. Densitometric profiles of immunoglobulin (Ig)G reactivity of a) 10 healthy individuals; b) 10 patients with idiopathic pulmonary arterial hypertension; c) 10 systemic sclerosis (SSc)associated pulmonary arterial hypertension (PAH) patients; d) 10 patients with limited cutaneous SSc without PAH; and e) 10 patients with diffuse SSc without PAH, to human epithelial (HEp)-2 cell antigens. Sera were diluted to an $\lg G$ concentration of $100 \mu \mathrm{g} \cdot \mathrm{mL}^{-1}$. The densitometric pattern of IgG reactivities of each individual is depicted as a full-line curve. Shaded areas depict the densitometric pattern observed in the presence of the secondary anti-crystallisable fragment$\gamma$ antibody alone. Molecular weights are expressed as $\mathrm{kDa}$ in the abscissa, and optical densities are expressed as arbitrary units (AU) in the ordinates.

phenotype of these cells [9]. Thus, IgG binding to the surface of fibroblasts could induce autocrine production of cytokines such as interleukin- $1 \alpha$, interleukin- $1 \beta$ and interleukin- 6 , which in turn could upregulate the expression of intercellular adhesion molecule (ICAM)-1 on the fibroblast surface [9]. Very few studies have been published regarding the specificity of anti-fibroblast antibodies. In SSc, DNA topoisomerase 1 was recently identified as the target of anti-fibroblast antibodies, with evidence that anti-topoisomerase 1 antibodies display anti-fibroblast activity by reacting with determinants at the fibroblast surface [17].

To the current authors' knowledge, anti-fibroblast antibodies have not previously been detected in the serum of patients with IPAH. PAH pathophysiology relies classically on an imbalance of intimal vasoconstrictors and vasodilators, decreased expression of potassium channels, adventitial increased expression of tenascin, inflammation, misguided 
TABLE 3 Factor analysis of repertoires of immunoglobulin $(\mathrm{lg}) \mathrm{G}$ and $\mathrm{IgM}$ from the sera of idiopathic pulmonary arterial hypertension (IPAH) patients, systemic scleroderma (SSc) patients with or without pulmonary arterial hypertension $(\mathrm{PAH})$ and their respective controls, on normal human fibroblasts and human epithelial (HEp)-2 cell antigens

\begin{tabular}{|c|c|c|c|c|c|c|c|c|}
\hline \multirow[t]{2}{*}{ Antigen source } & \multirow[t]{2}{*}{ Isotype } & \multirow[t]{2}{*}{ Factor } & \multicolumn{2}{|c|}{ PAH versus controls } & \multicolumn{2}{|c|}{ IPAH versus controls } & \multicolumn{2}{|c|}{ SSc PAH versus controls } \\
\hline & & & $\begin{array}{l}\text { Molecular weights } \\
\text { kDa }\end{array}$ & p-value & $\begin{array}{c}\text { Molecular weights } \\
\text { KDa }\end{array}$ & p-value & Molecular weights kDa & p-value \\
\hline \multirow{5}{*}{ Fibroblasts } & $\lg G$ & 1 & $30,35,40,60$ & $<0.001^{\#}$ & $30,35,40,60$ & $<0.001^{\#}$ & $30,35,40,60,95$ & 0.557 \\
\hline & & 2 & 25,95 & $<0.001$ & 25,95 & $<0.001^{\#}$ & 25,60 & 0.084 \\
\hline & $\lg M$ & 1 & 65,70 & $0.003^{\#}$ & $25,30,35,95$ & $0.008^{\#}$ & $25,30,50,75,85$ & 0.275 \\
\hline & & 3 & 70,95 & 0.456 & $50,75,85$ & $<0.001^{\#}$ & 70,95 & 0.922 \\
\hline & $\lg G$ & 1 & $25,30,35,50,75,85$ & 0.367 & 65,70 & 0.367 & 65,70 & 0.367 \\
\hline \multirow{4}{*}{ HEp-2 cells } & & 2 & 35,40 & 0.795 & 45,65 & 0.795 & 45,65 & 0.795 \\
\hline & & 3 & 70,95 & 0.122 & 25,35 & 0.122 & 25,35 & 0.122 \\
\hline & $\lg M$ & 1 & $35,45,50,73,75$ & 0.1 & $30,45,50,73,75$ & 0.06 & $55,65,70,75$ & 0.37 \\
\hline & & 2 & $55,65,70$ & 0.27 & 25,30 & 0.24 & $25,30,35,45,50,73,75$ & 0.85 \\
\hline
\end{tabular}

\#: level of significance of the comparison of the factor scores of patients with controls using a paired Wilcoxon test.

angiogenesis and hypercoagulability [18]. Genetic susceptibility is important in $\mathrm{PAH}$, since mutations in the type 2 transforming growth factor (TGF)- $\beta$ receptor gene are present in $\sim 30 \%$ of plexiform lesions [19]. Germ-line mutations of bone morphogenic protein receptor (BMPR)-II, a member of the TGF- $\beta$ receptor family, are well documented in familial, idiopathic and fenfluramine-associated PAH. Interestingly, no mutation of the gene coding for BMPR-II has been identified in SSc patients with PAH [20].

There is some evidence suggesting a role for an auto-immune process in $\mathrm{PAH}$ [21]. Indeed, $\mathrm{PAH}$ is a common complication of autoimmune diseases such as SSc, mixed connective tissue disease and systemic lupus erythematosus [4]. Pulmonary arterial lesions in the lungs of patients suffering from $\mathrm{PAH}$ associated with connective tissue diseases are similar to those found in IPAH [3]. This resemblance in pathological anatomy may suggest similar mechanisms. Besides medial hypertrophy, intimal "onion bulb" lesions and characteristic glomoid-like plexiform lesions, CoOL et al. [22] have reported that in patients with SSc-related $\mathrm{PAH}$, mononuclear inflammatory cells surround vascular sites of plexiform growth, but not uninvolved vessels or extravascular lung structure. In in vitro experiments, auto-antibodies from patients with connective tissue diseases, including anti-U1-ribonucleoprotein antibodies and anti-double-stranded DNA antibodies, induced up-regulation of the expression of ICAM-1, endothelium leukocyte adhesion molecule 1 and major histocompatibility complex

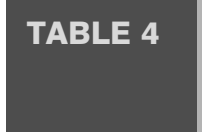

Antigen source

Factor analysis of repertoires of immunoglobulin (Ig)G and IgM from sera of idiopathic pulmonary arterial hypertension (IPAH) patients, systemic sclerosis (SSc) patients with or without pulmonary arterial hypertension (PAH), compared two by two, on normal human fibroblasts and human epithelial (HEp)-2 cell antigens

\begin{tabular}{|c|c|c|c|c|c|c|}
\hline \multirow[t]{2}{*}{ Antigen source } & \multirow[t]{2}{*}{ Isotype } & \multirow[t]{2}{*}{ Factors } & \multicolumn{2}{|c|}{ SSc-PAH versus IPAH } & \multicolumn{2}{|c|}{ SSc-PAH versus SSc without PAF } \\
\hline & & & Molecular weights kDa & p-value & Molecular weights kDa & p-value \\
\hline & $\lg G$ & 1 & $60,40,35,30,25$ & 0.32 & $35,30,25$ & 0.553 \\
\hline & & 2 & & & $95,60,40$ & 0.582 \\
\hline \multirow[t]{5}{*}{ Fibroblasts } & $\lg M$ & 1 & 65,70 & 0.486 & $25,35,45$ & 0.912 \\
\hline & & 2 & 45,55 & 0.257 & 55,65 & 0.524 \\
\hline & & 3 & 25,35 & 0.614 & 70 & 0.367 \\
\hline & $\lg G$ & 1 & $25,30,35,50,75,85$ & $0.003^{\#}$ & $25,30,50,75,85$ & $0.002^{\#}$ \\
\hline & & 2 & 35,40 & 0.712 & $50,70,95$ & 0.441 \\
\hline \multirow[t]{4}{*}{ HEp-2 cells } & & 3 & 70,95 & $<0.001^{\#}$ & $25,35,40$ & $<0.001^{\#}$ \\
\hline & $\lg M$ & 1 & $32,45,50,73,75$ & 0.78 & $25,28,45,50,55$ & 0.95 \\
\hline & & 2 & 65,68 & 0.5 & 65,68 & 0.61 \\
\hline & & 3 & $25,28,55$ & 0.8 & 73,77 & 0.09 \\
\hline
\end{tabular}


class II molecules on the surface of human pulmonary endothelial cells, suggesting that such an inflammatory process could lead to proliferative and inflammatory pulmonary vasculopathy [23].

By contrast, less data are available regarding the detection of auto-antibodies in other subgroups of $\mathrm{PAH}$ patients. Nevertheless, in a significant proportion of IPAH patients there is evidence of auto-immunity and/or active inflammation, including detection of circulating autoantibodies [8, 24], elevated serum levels of the pro-inflammatory cytokines interleukin (IL)-1 and IL-6, and increased pulmonary expression of platelet-derived growth factor or chemokines [3]. Some studies suggest a close association of IPAH and auto-immune thyroid disease, further supporting the possibility of an autoimmune mechanism in PAH [25]. In the present study, anti-fibroblast antibodies identified in the serum of IPAH patients were shown to express a major reactivity with a 60$\mathrm{kDa}$ protein band, whereas IgG reactivities directed toward 70-, 75- and 95-kDa bands were specific to SSc patients, since none of those are shared with IgG from idiopathic PAH patients. The absence of IgG immunoreactivity with a $60-\mathrm{kDa}$ band in HEp-2 cell extracts suggests the fibroblast specificity of IgG anti-fibroblast antibodies in IPAH patients. However, the current authors have previously reported that IgG from the same IPAH patients also bound to a $60-\mathrm{kDa}$ protein in macrovascular endothelial cells, although this $60-\mathrm{kDa}$ band was not present when sera were tested with microvascular lung and dermal endothelial cells [8]. Moreover, the present experiments were performed at an $\operatorname{IgG}$ concentration of $100 \mu \mathrm{g} \cdot \mathrm{mL}^{-1}$, whereas previous experiments regarding antiendothelial cell antibodies in IPAH patients were performed at an $\mathrm{IgG}$ concentration of $200 \mu \mathrm{g} \cdot \mathrm{mL}^{-1}$. Finally, the current authors have failed to show any significant difference between antibody reactivities from IPAH patients and from SSc patients with PAH, as well as between SSc patients with PAH and healthy controls. This absence of significant differences might be the consequence of the small number of SSc patients tested.

The target antigens of anti-fibroblast antibodies in PAH have not yet been identified. It is possible to speculate, since IgG anti-fibroblast antibodies bind to unpermeabilised fibroblasts as assessed by ELISA, that the target antigen(s) might be part of the fibroblast membrane. Whether these anti-fibroblast IgG antibodies arise as a consequence of overexpression of cellsurface antigens in the context of increased fibroblast proliferation, or from primary auto-immune reaction, is a matter of speculation. An attractive hypothesis would be to link these anti-fibroblast antibodies with structural abnormalities of cellsurface receptors that might result from genetic abnormalities i.e. of TGF- $\beta$ receptor superfamily genes. The target antigens of IgG and IgM anti-fibroblast antibodies need to be characterised, as does their potential pathogenic role. Thus, irrespective of their exact target antigen, it is speculated that these auto-antibodies may induce an activating signal leading to cell proliferation and the release of mediators including cytokines, chemokines and growth factors which could contribute to the development of PAH [3].

For the first time, the current authors provide evidence that patients with idiopathic pulmonary arterial hypertension and pulmonary arterial hypertension associated with systemic sclerosis express anti-fibroblast antibodies. The target antigens and the potential pathogenic role of those antibodies remain to be determined [16]. The predictive value of these antibodies in patients at risk of developing pulmonary arterial hypertension, such as systemic sclerosis patients and patients with a familial history of pulmonary arterial hypertension, needs to be investigated.

\section{ACKNOWLEDGEMENTS}

The authors would like to thank F. Batteux, who provided HEp-2 cells.

\section{REFERENCES}

1 Rubin LJ. Primary pulmonary hypertension. N Engl J Med 1997; 336: 111-117.

2 Barst RJ, McGoon M, Torbicki A, et al. Diagnosis and differential assessment of pulmonary arterial hypertension. J Am Coll Cardiol 2004; 43: Suppl. 12, 40S-47S.

3 Humbert M, Morrell NW, Archer SL, et al. Cellular and molecular pathobiology of pulmonary arterial hypertension. J Am Coll Cardiol 2004; 43: Suppl. 12, 13S-24S.

4 Simonneau G, Galie N, Rubin LJ, et al. Clinical classification of pulmonary hypertension. J Am Coll Cardiol 2004; 43: Suppl. 12, 5S-12S.

5 Sitbon O, Gressin V, Speich R, et al. Bosentan for the treatment of human immunodeficiency virus-associated pulmonary arterial hypertension. Am J Respir Crit Care Med 2004; 170: 1212-1217.

6 Hachulla E, Gressin V, Guillevin L, et al. Early detection of pulmonary arterial hypertension in systemic sclerosis: a French nationwide prospective multicenter study. Arthritis Rheum 2005; 52: 3792-3800.

7 Stenmark KR, Gerasimovskaya E, Nemenoff RA, Das M. Hypoxic activation of adventitial fibroblasts: role in vascular remodeling. Chest 2002; 122: Suppl. 6, 326S-334S.

8 Tamby MC, Chanseaud Y, Humbert M, et al. Antiendothelial cell antibodies in idiopathic and systemic sclerosis associated pulmonary arterial hypertension. Thorax 2005; 60: 765-772.

9 Chizzolini C, Raschi E, Rezzonico R, et al. Autoantibodies to fibroblasts induce a proadhesive and proinflammatory fibroblast phenotype in patients with systemic sclerosis. Arthritis Rheum 2002; 46: 1602-1613.

10 LeRoy EC, Medsger TA Jr. Criteria for the classification of early systemic sclerosis. J Rheumatol 2001; 28: 1573-1576.

11 Masi AT, Rodnan GP, Medsger TA, et al. Preliminary criteria for the classification of systemic sclerosis (scleroderma). Arthr Rheum 1980; 23: 581-590.

12 Moloney M, McDonnell L, O'Shea $\mathrm{H}$. Atomic force microscopy of BHK-21 cells: an investigation of cell fixation techniques. Ultramicroscopy 2004; 100: 153-161.

13 Garcia de la Pena-Lefebvre P, Chanseaud Y, Tamby MC, et al. IgG reactivity with a $100-\mathrm{kDa}$ tissue and endothelial cell antigen identified as topoisomerase 1 distinguishes between limited and diffuse systemic sclerosis patients. Clin Immunol 2004; 111: 241-251.

14 Chanseaud Y, Tamby MC, Guilpain P, et al. Analysis of autoantibody repertoires in small- and medium-sized vessels vasculitides. Evidence for specific perturbations in polyarteritis nodosa, microscopic polyangiitis, 
Churg-Strauss syndrome and Wegener's granulomatosis. J Autoimmun 2005; 24: 169-179.

15 Harman HH. Modern Factor Analysis. 2nd Edn. Chicago, The University Of Chicago Press, 1967.

16 Mouthon L, Guillevin L, Humbert M. Pulmonary arterial hypertension: an autoimmune disease? Eur Respir J 2005; 26: 986-988.

17 Henault J, Tremblay M, Clement I, Raymond Y, Senecal JL. Direct binding of anti-DNA topoisomerase I autoantibodies to the cell surface of fibroblasts in patients with systemic sclerosis. Arthritis Rheum 2004; 50: 3265-3274.

18 Eddahibi S, Morrell N, d'Ortho MP, Naeije R, Adnot S. Pathobiology of pulmonary arterial hypertension. Eur Respir J 2002; 20: 1559-1572.

19 Yeager ME, Halley GR, Golpon HA, Voelkel NF, Tuder RM. Microsatellite instability of endothelial cell growth and apoptosis genes within plexiform lesions in primary pulmonary hypertension. Circ Res 2001; 88: 2-11.

20 Morse J, Barst R, Horn E, Cuervo N, Deng Z, Knowles J. Pulmonary hypertension in scleroderma spectrum of disease: lack of bone morphogenetic protein receptor 2 mutations. J Rheumatol 2002; 29: 2379-2381.

21 Nicolls MR, Taraseviciene-Stewart L, Rai PR, Badesch DB, Voelkel NF. Autoimmunity and pulmonary hypertension: a perspective. Eur Respir J 2005; 26: 1110-1118.

22 Cool CD, Kennedy D, Voelkel NF, Tuder RM. Pathogenesis and evolution of plexiform lesions in pulmonary hypertension associated with scleroderma and human immunodeficiency virus infection. Hum Pathol 1997; 28: 434-442.

23 Okawa-Takatsuji M, Aotsuka S, Fujinami M, Uwatoko S, Kinoshita M, Sumiya M. Up-regulation of intercellular adhesion molecule-1 (ICAM-1), endothelial leucocyte adhesion molecule-1 (ELAM-1) and class II MHC molecules on pulmonary artery endothelial cells by antibodies against U1ribonucleoprotein. Clin Exp Immunol 1999; 116: 174-180.

24 Isern RA, Yaneva M, Weiner E, et al. Autoantibodies in patients with primary pulmonary hypertension: association with anti-Ku. Am J Med 1992; 93: 307-312.

25 Chu JW, Kao PN, Faul JL, Doyle RL. High prevalence of autoimmune thyroid disease in pulmonary arterial hypertension. Chest 2002; 122: 1668-1673. 